\title{
Assessment of physiological strain in inland fishing activity
}

\begin{abstract}
Ten fishermen aged between 19 and 48 years of age, were examined in the field during inland fishing activity, which they perform individually. Physiological strain in terms of heart rate varied between 86 and 115 beats/min with mean net cardiac cost of 32 beats $/ \mathrm{min}$. The average relative cardiac cost was $36 \%$. Analysis of physiological responses revealed that the recommended limits of cardiac strain indices were surpassed during the majority of the fishing period. Average energy cost was estimated to be $3.3 \mathrm{kcal}$.min-1, which was about $34 \%$ of the VO2max. Average intensity of the workload entailed in the whole fishing shift appeared to be moderate and acceptable. Furthermore, the heat load in the working situation did not appear to be a serious threat to the health of the workers. Analysis of work revealed more static exertions in the work. To reduce the postural load and musculoskeletal discomforts of the fishermen, ergonomic interventions are required, which represents a further scope of study.
\end{abstract}

Key words: Cardiac strain, energy expense, heart rate, inland fishing, physiological strain, $\mathrm{VO}_{2} \max$

\section{INTRODUCTION}

Inland fishing has been a very important component of rural economy and an integral part of life and culture of India since time immemorial. Different varieties of inland fishing methods are practiced in the nook and corner of the country that are yet to taste the fervor of any mechanization, and manual labor is still obligatory in this profession. Occupational health studies among the inland fishermen represent a virgin area. Till date no systemic work-physiological studies have been conducted to evaluate the work stress of fishermen engaged in this occupation. However, overseas values of energy output and work stress in coastal and trawler fishing have indicated that fishing may be considered as a job of arduous nature..$^{[1-4]}$ The present study encompasses a work-physiological examination on a common inland fishing task performed by individual fishermen. The study is exploratory in nature, and the primary objective is to determine the magnitude of physiological strain of the fishermen in actual situation of work.

\section{MATERIALS AND METHODS}

\section{Time and location}

The study was conducted in two places of Hooghly district in West Bengal, viz., Chandannagar and Rishra, during the month of April-June 2001. The locations were selected meticulously - population of fishermen frequenting these areas so that suitable follow-up studies could be undertaken.

\section{Subjects}

After selection of the sites, interactions were carried out with the fishermen at weekly intervals for a a period of one month, when the fishermen were motivated to cooperate as required by the design of the study. After a careful and repeated follow-up, a total of 10 professional fishermen were selected.

\section{Description of the fishing task}

A special fishing tackle, resembling a sieve, is used for fishing. This is made by mounting nets on circular or triangular bamboo frames and is called 'Bhasali' in local parlance.

Individual fishermen wade in knee- to waist-deep water and immerse this scoop net with a few strides in a bent position. The immersed entrapment is lifted, excess water is allowed to flow out, and the catches entrapped within the net are transferred to a container, usually strapped to the fisherman's waist.

\section{Laboratory investigation}

Maximal heart rate (HRmax) and maximal oxygen consumption $\left(\mathrm{VO}_{2}\right.$ max) were measured in the laboratory using a maximal bicycle
R. Biswas,

A. Samanta Department of Occupational Health All India Institute of Hygiene and Public Health 110, Cittaranjan Avenue,

Kolkata-700 073, India

For correspondence:

A. Samanta,

Department of

Occupational Health

All India Institute of Hygiene and Public

Health 110, Cittaranjan Avenue,

Kolkata-700 073, India. E-mail:

ergoraj@rediffmail.com 
ergometry test ${ }^{[5]}$ and expressed in beats. min $^{-1}$ and $\mathrm{ml} . \mathrm{kg}^{-1}$ min $^{-1}$ respectively. Prediction equations for all the subjects were obtained in the form of linear regression using the initial, final and intermediate set of values of heart rate as the predictor variable and oxygen consumption as the criterion variable obtained during the test. Lowest heart rate recorded during a minimum rest period of $30 \mathrm{~min}$ in comfortable room temperature in the laboratory was considered as the resting heart rate (RHR). Heart rate reserve (HRR) of the subjects was obtained as the difference between the HR max and RHR and was also expressed in beats. $\mathrm{min}^{-1}$.

\section{Field Investigation}

In field working heart rate (WHR) was obtained in an unobtrusive way by means of lightweight telemetric equipment - Sports Tester PE 3000 (Polar Electro, Finland) at every 15-s interval. From these heart rates, oxygen consumption (VO) was predicted from $\mathrm{VO}_{2}=f(\mathrm{HR})$ relationship established in the laboratory test. Recovery heart rates were measured just after the cessation of work cycle. ${ }^{[6]}$ Relative cost of work was determined in terms of relative aerobic strain (RAS) by expressing the VO as the percentage of maximal aerobic capacity $\left(\% \mathrm{VO}_{2} \max \right)$ of the subjects. Relative cardiac cost was obtained by expressing the WHR as the percentage of the heart rate reserve (\%HRR) of the subjects. Net cardiac cost was obtained as the difference between WHR and RHR and expressed in beats/min. Perceived exertion was measured according to Borg's scale. ${ }^{[7]}$ Corrected effective temperature (CET) was measured as an index of heat stress to ascertain the environmental heat load. Each fisherman was studied on a single day while he was regularly engaged in the task. The time for the study varied between 7 to $11 \mathrm{~h}$ for different study days. During the study, the fishermen maintained their normal pace of work, and no instructions were given to them to control their work pace and methods as it may interfere with the primary objective of the study.

\section{RESULTS}

\section{Physical and physiological characteristics of the subjects}

Descriptive statistics of all the 10 fishermen studied is presented in the Table 1. The mean age of the fishermen was $31.6 \pm 11.3$ years, and work experience varied between 4 and 32 years. The mean BMI for the group was obtained to be $19.8 \pm 0.64 \mathrm{~kg} \cdot \mathrm{m}^{-2}$. It is apparent that the height and weight of the subjects are typical of the average populations from eastern India. Mean $\mathrm{HRmax}$ and $\mathrm{VO}_{2}$ max obtained in bicycler ergometry were $161 \pm 8.1$ beats. $\mathrm{min}^{-1}$ and $38.8 \mathrm{ml} . \mathrm{kg}^{-1} \cdot \mathrm{min}^{-1}$ respectively.

\section{Physiological strain in the fishing task}

Physiological strain in scoop net fishing is expressed in Table 2.
Table 1: Characteristics of the subjects $(n=10)$

\begin{tabular}{|c|c|c|c|}
\hline Parameters & Mean & SD & Range \\
\hline Age (years) & 31.6 & 11.3 & $20-54$ \\
\hline Height $(\mathrm{cm})$ & 159.5 & 4.9 & $154.5-170.0$ \\
\hline Weight $(\mathrm{kg})$ & 50.3 & 3.3 & $46.5-57.4$ \\
\hline BMI (kg. $\left.\mathrm{m}^{-2}\right)$ & 19.8 & 0.64 & $18.7-21.0$ \\
\hline Experience (years) & 13.7 & 8.3 & $4-32$ \\
\hline Resting heart rate (beats. min $^{-1}$ ) & 75 & 6.8 & $65-86$ \\
\hline Maximal heart rate (beats. $\min ^{-1}$ ) & 161 & 8.1 & $143-170$ \\
\hline Maximal oxygen consumption $\left(\mathrm{ml}^{-\mathrm{kg}^{-1}} \cdot \mathrm{min}^{-1}\right)$ & 38.8 & 3.6 & $32.7-43.0$ \\
\hline
\end{tabular}

Table 2: Cardiac strain, metabolic cost and perceived exertion during fishing with scoop net. $(n=10)$

\begin{tabular}{|c|c|c|c|}
\hline Variables & Mean & SD & Range \\
\hline Mean work day pulse (beats. min $^{-1}$ ) & 106 & 6.2 & $95-113$ \\
\hline Net cardiac cost (beats. min $^{-1}$ ) & 31 & 3.7 & $25-37$ \\
\hline Relative cardiac cost (\%) & 36 & 3.9 & $30-43$ \\
\hline Recovery heart rate 1 (beats. $\min ^{-1}$ ) & 93 & 6.3 & $84-104$ \\
\hline Recovery heart rate 2 (beats. min $^{-1}$ ) & 82 & 7.2 & $70-94$ \\
\hline Recovery heart rate 3 (beats. min $^{-1}$ ) & 81 & 6.0 & $70-90$ \\
\hline Brouha's index & -12.3 & 4.3 & $-20.0--4.0$ \\
\hline Oxygen consumption (ml. $\left.\mathrm{kg}^{-1} \cdot \mathrm{min}^{-1}\right)$ & 13.2 & 1.1 & $11.1-15.1$ \\
\hline Relative aerobic strain ( $\%$ of $\mathrm{V}_{2} \max$ ) & 34 & 2.8 & $30-38$ \\
\hline Energy expenditure (kcal. $\left.\mathrm{min}^{-1}\right)$ & 3.3 & 0.4 & $2.7-3.9$ \\
\hline Perceived exertion & 10.0 & 0.6 & $9-11$ \\
\hline
\end{tabular}

The mean values for all the parameters calculated from the subjects' means indicated that the mean workday heart rate of the fishermen varied between 95 and 113 beats. min ${ }^{-1}$. Average net cardiac cost and relative cardiac cost was $31 \pm 3.7$ beats. $\mathrm{min}^{-1}$ and $36 \pm 3.9 \%$ respectively. The table also indicates that the fishermen have utilized 30 to $38 \%$ of their maximal aerobic power during fishing with an average oxygen uptake of $13.2 \pm 1.1 \mathrm{ml} . \mathrm{kg}^{-1}$. $\mathrm{min}^{-1}$ (range 11.1-15.1) that corresponded to an average energy expenditure of $3.3 \pm 0.4$ $\mathrm{kcal}$. $\mathrm{min}^{-1}$. Recovery heart rate pattern indicates that the first minute recovery heart rate was only $93 \pm 6$. 3 beats. $\mathrm{min}^{-1}$, which is well below the recommended criteria ${ }^{[6]}$ with a mean pulse deceleration index of $-12.3 \pm 4.3$ beats. $\mathrm{min}^{-1}$. For two of the fishermen, the pulse deceleration index was above the recommended limit of -10 beats. $\mathrm{min}^{-1}$.

For a cursory examination of the physical strain experienced by the fishermen, a 90-min averaged heart rate curve was constructed (Figure 1) on the basis of mean heart rate of all the fishermen in each minute of the fishing period, which indicates the pattern of heart rate in the whole work shift. As displayed in the figure, the overall mean working heart rate was $41 \%$ higher than the mean resting heart rate although occasional peaks with $47 \%$ increment were also found. It is also noticeable from the figure that the periods of tachycardia (heart rate more than 100 beats. min $^{-1}$ ) started at the $16^{\text {th }}$ minute of fishing and continued throughout the whole shift and accounted for $53 \%$ of the total fishing period. It is also apparent from the figure that initially the heart rate increased from 91 to 109 beats. $\mathrm{min}^{-1}$ in the first 30 min of fishing period, after which it attained a more or less steady pattern. 


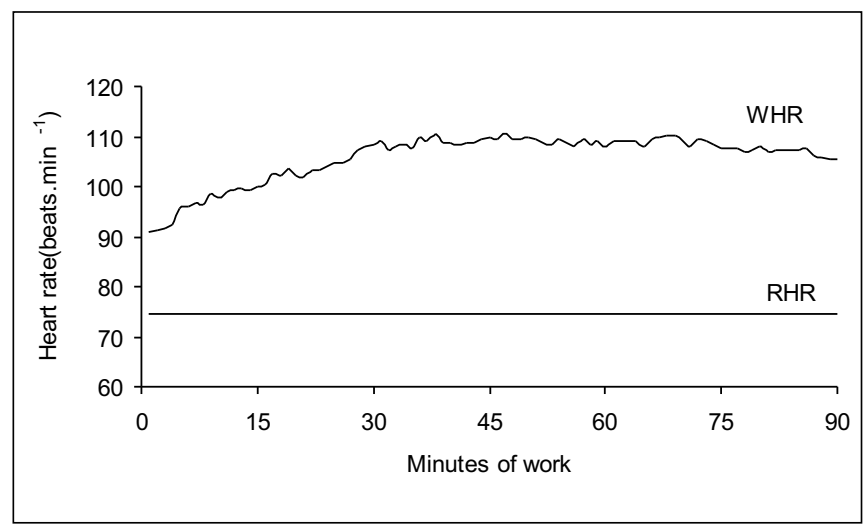

Figure 1: Average heart rate curve of the fishermen $(n=10)$, during fishing with a scoop net for 90 minutes of work

For more detailed insight into the physical strain, the relative cardiac costs were divided into regular class intervals and plotted against time expressed as the percentage of the total working period (Figure 2). It can be seen from the figure that for most of the time in a workday, the physical strain remained below $50 \%$, and for majority of the fishing period, the fishermen worked at a level of $31-40 \%$ of their heart rate reserve.

The average workload of the individual fishermen was also judged against various recommended indices of physical strain in relation to mean working heart rate, mean net cardiac cost and mean relative cardiac cost. The results are summarized in Table 3. It can be observed from the table that for two fishermen (20\%), the mean workday pulse exceeded the recommended limit of continuous work. In contrast, $70 \%$ of the mean net cardiac costs and $90 \%$ of the mean relative cardiac costs were higher than the accepted limit.

Duration of work periods exceeding cardiac strain limits was analyzed for individual fishermen as summarized in Table 4. On an average, for $34.4 \%$ of the total work-period heart rates were above 110 beats. $\mathrm{min}^{-1}$ and for $54.4 \%$ of the total work period, the net cardiac costs were higher than 30 beats. min 1. For $3 \%$ of the total duration of work, the relative cardiac costs of the fishermen were higher than $50 \%$. It is also clear from the table that the fishermen did not respond equally during the work shift, as is evident from the range of the length of duration for which the recommended ranges were

Table 3: Percentage of fishermen exceeding the recommended limits of physical strain

\begin{tabular}{lcc}
\hline Indices & Accepted limits & $\begin{array}{c}\text { Percentage of } \\
\text { fishermen }\end{array}$ \\
\hline Mean workday pulse over & 35 beats over resting & 20 \\
limit for continuous work & sitting pulse & 70 \\
Net cardiac cost & 30 beats.min ${ }^{-1}$ & 90 \\
Relative cardiac cost & $30 \%$ & 20 \\
Brouha's Index & -10 beats. min $^{-1}$ & \\
\hline
\end{tabular}

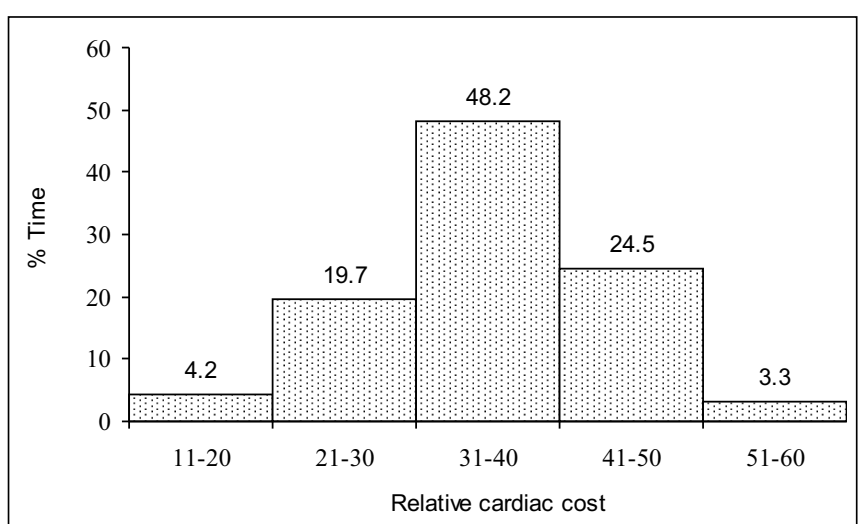

Figure 2: Mean distribution of cumulative time (percentage of the total working period) at different physical strain levels(RCC) of the fishermen during fishing with a scoop net

surpassed, particularly with respect to working heart rate and net cardiac costs.

Environmental conditions at the workplace are summarized in Table 5. Mean CET at the workplace was obtained to be $29.3^{\circ} \mathrm{C}$.

\section{DISCUSSION}

\section{Physical strain of the fishing task}

Heart rate is the principal parameter monitored in the field. It not only permits the evaluation of circulatory strain imposed by the workloads of varying intensity ${ }^{[6]}$ with minimal interference with the subject's freedom of motion and performance ability, but it also provides an integrated response to energy requirement and thermal and postural demand..$^{[8]}$ It is also suitable for field studies, as a number of recordings can be made during the whole work in contrast to the inconvenience of measuring oxygen consumption. ${ }^{[9]}$

Other than absolute heart rate, net cardiac costs and relative

Table 4: Percentage of total work periods in scoop net fishing exceeding various physical strain levels

\begin{tabular}{lccc}
\hline Variables & $\begin{array}{c}\text { Physical strain } \\
\text { level }\end{array}$ & \multicolumn{2}{c}{$\begin{array}{c}\text { Duration of fishing period } \\
\text { exceeding physical strain levels }\end{array}$} \\
\cline { 3 - 4 } & & (min) & $(\%)$ \\
\hline Working heart rate & 110 beats.min ${ }^{-1}$ & $32.3(0-68)^{*}$ & $34.4(0-71)$ \\
Relative cardiac cost & $30 \%$ & $71.1(40-88)$ & $76.1(42-92)$ \\
Relative cardiac cost & $50 \%$ & $3.1(0-14)$ & $3.3(0-15)$ \\
Net cardiac cost & 30 beats.min ${ }^{-1}$ & $50.9(10-86)$ & $54.4(11-90)$ \\
\hline
\end{tabular}

${ }^{*}$ mean (range)

Table 5: Environmental conditions at the workplace

\begin{tabular}{lcc}
\hline Parameters & Mean & SD \\
\hline Dry bulb temperature $\left({ }^{\circ} \mathrm{C}\right)$ & 31.3 & 0.83 \\
Wet bulb temperature $\left({ }^{\circ} \mathrm{C}\right)$ & 27.1 & 0.58 \\
Globe temperature $\left({ }^{\circ} \mathrm{C}\right)$ & 38.0 & 1.83 \\
Air velocity $\left(\mathrm{ft} . \mathrm{min}^{-1}\right)$ & 170.1 & 40.4 \\
CET $\left({ }^{\circ} \mathrm{C}\right)$ & 29.3 & 0.76 \\
\hline
\end{tabular}


cardiac costs ${ }^{[10,11]}$ were derived as indices of cardiac strain. As heart rate response to one and the same work load is sensitive to many inter- and intra-individual influences, ${ }^{[12,13]}$ choice of these derived indices were made in this present study as they take into account the inter-individual differences. ${ }^{[14]}$ Moreover, net cardiac cost, being related to resting heart rate, evaluates the work load strictly connected with the job; while the relative cardiac cost, taking into consideration both the resting and maximal heart rate of the subjects, gives best expression of the individual circulatory strain. ${ }^{[15,16]}$ Such a view also oriented the choice for 'limit for continuous work ${ }^{\prime[17]}$ adjusted for male population and based on the resting pulse of the subjects. In this study, working oxygen consumptions were estimated from measured working heart rates as a general linear relationship exists between the parameters during standardized exercise as obtained in this study during laboratory examination ${ }_{i}$ that corroborates well with earlier findings. ${ }^{[18]}$ As this sort of estimation is reliable for all practical purposes of field investigation and is quite sensitive with a variation of $\pm 15 \%{ }^{[18]}$ estimated values were used to assess the relative degree of physical exertion by expressing the oxygen uptake as percentage of subject's maximal aerobic power. Responses were cross-examined against certain recommended criteria of physical strain, which allows a better evaluation of strain in relation to different parameters.

The physical strain of the present inland fishing task in terms of heart rate could be compared with the tasks related with apple farming ${ }^{[15]}$ and dairy farming works. ${ }^{[19]}$ The relative aerobic strain in the scoop net fishing varied between 30 and $38 \%$ of $\mathrm{VO}_{2}$ max, which compared with the values obtained for different types of coastal fishing tasks, viz., hand line, long line and net fishing but was lower than the strain of fishing with a Danish-seine. ${ }^{[2]}$ Values of energy cost are also comparable with some aspects of agricultural works, stone cutting, textile and jute mill works. ${ }^{[20-23]}$

\section{Analysis of work activities}

The average length of the total duration of fishing period was 93.4 \pm 3.5 min, during which the fishermen made 7 to 11 fishing attempts. Wading, stooping and catch-handling are the main activities noted. Observations on these tasks indicate the presence of predominant static components in the whole work that comprises bending postures during fishing, and static contractions of arms during holding and cleaning the entrapment and collecting the entrapped fishes. Static muscular contractions were also required during prolonged standing and wading in water to adjust postural disequilibrium. Besides, every time the fisherman bent his trunk to dip his entrapment in water, a new cycle is initiated that ends in sorting and collecting the catch. This cyclic pattern of work (with average cycle time of $10 \mathrm{~min}$ ) represents a nonsteady work phase that might prevent the workers from full recovery in between successive work cycles. The recovery pattern of the fishermen revealed that although the recovery heart rates were well within the recommended range, the pulse deceleration index was higher than the recommended range of -10 beats. min $^{-1[6]}$ which may be due to the predominant static load of the work.

\section{Environmental conditions}

Environmental conditions of the workplaces of the fishing jobs are shown in Table 5, comprising dry bulb, wet bulb and globe temperature along with wind velocity. For the purpose of evaluation of the environmental heat load, the CET is considered. The present findings indicated that the work output of the fishermen was $198 \mathrm{kcal}^{\mathrm{hr}} \mathrm{r}^{-1}$ at an average CET of $84.7^{\circ} \mathrm{F}$. This level of energy expense in relation to environmental heat load could be considered well within the acceptable level of energy expense within the 'prescriptive zone.' ${ }^{[25,26]}$ Furthermore, the total working time (90-101 min) was also much less than the work pattern for the industrial workers ( $480 \mathrm{~min}$ ). So from these results, it could be suggested that the actual prevailing temperature in the workplace was not a threat to the health of the fishermen.

\section{Heaviness of the task}

The physiological gradations of different activities have been proposed by different researchers in the field of work physiology and ergonomics from time to time. They are either based on the monitoring of some principal parameters like heart rate both during work ${ }^{[18]}$ and recovery ${ }_{1}^{[6,27]}$ energy $\operatorname{cost}^{[28]}$ or on some derived parameters like net cardiac cost. ${ }^{[11]}$ Based on these scales of heaviness, it appeared that fishing with scoop net represented a work of moderate intensity.

\section{Rationalization of the fishing tasks}

The knowledge of acceptable workload is of great practical importance in the field of work physiology in order to rationalize a task because often the workload for a particular task is so heavy that it imposes undue physiological strain on the workers and results in fatigue that leads to gradual decrement of work capacity. A number of earlier studies have attempted to establish an optimal work rate limit expressed in terms of relative aerobic strain $\left(\% \mathrm{VO}_{2 \max }\right)$ appropriate for specific occupational tasks. For a relatively homogenous group of individuals, the average value of this parameter therefore may be considered as the reasonable upper limit for continuous work stretching over several hours. This assumption is also equally applicable for Indian workers. ${ }^{[29]}$ It was found during the study that the fishermen maintained their usual pace of work without any compromise with the actual usual length of work shift and on average have utilized $34 \%$ of their $\mathrm{VO}_{2} \max$, which is not only lower than the recommended level for Indians, ${ }^{[29]}$ but also lower than the acceptable level of 41 and $45 \%$ for a mixed dynamic and static work ${ }^{[30]}$ and self-paced sustained physical work of 1-2 hours' 
duration $^{[31]}$ respectively. It was established that the heart rate in terms of relative cardiac cost is also an equally reliable measure to rationalize the physiological workload since the later showed better correlation with the relative aerobic strain. ${ }^{[19]}$ In the present study, the average value of relative cardiac cost was around $36 \%$, which is almost similar to the value of the acceptable level of relative aerobic strain for Indians. ${ }^{[29]}$ Furthermore, as the inland fishing task as investigated in the present study represents a work stretching much less than $480 \mathrm{~min}$, as with industrial operations, the acceptable limit for the fishermen engaged in different fishing tasks could be set on a higher side than that set for different tasks spanning $8 \mathrm{~h}$. From these facts, it therefore seems to indicate that the workload of the fishermen was within the acceptable limit.

\section{CONCLUSION}

Although the occupation appeared to be a work of moderate intensity, the presence of predominant static effort in every aspect of the job could not be ignored, as it could be detrimental particularly for the elderly workers and might cause musculoskeletal disorders among this group of fishermen. Ergonomic intervention programs could be implemented to reduce the overall static load of the fishermen. Furthermore, evaluation of musculoskeletal signs and symptoms in the fishermen is also required to be done, all of which represents a further scope for study.

\section{ACKNOWLEDGMENT}

The authors are grateful to the Director, All India Institute of Hygiene and Public Health, for providing necessary facilities for conducting the study. The authors are also duty-bound to express their gratitude to the fishermen who volunteered for the study.

\section{REFERENCES}

1. Astrand I, Fugelli P, Karlsson CG, Rodahl K, and Vokac Z. Energy output and work stress in coastal fishing. Scandinavian Journal of Clinical and Laboratory Investigation 1973;31;105-13.

2. Rodahl K, Vokac Z, Fugelli O, Vaage O, Maehlum S. Circulatory strain, estimated energy output and Catecholamine excretion in Norwegian coastal fishermen. Ergonomics 1974;17;585-602.

3. Rodahl K, Vokac Z. Work stress in Norwegian trawler fishermen. Ergonomics 1977;20;633-42.

4. Rodahl K, Vokac Z. Work stress in long line bank fishing. Scandinavian Journal of work environment and Health. 1977;3;154-9.

5. Aminoff T, Smolander J, Korhonen O and Louhevaara V. Physiological strain during kitchen work in relation to maximal and task specific peak values. Ergonomics 1999;42:584-92Grandjean E:Précis d'Ergonomie. Les éditions d'organisation, Paris 1983;416.

6. Brouha L. Evaluation of the physiological requirements of Jobs. In Physiology in Industry:Evaluation of Industrial. stress by the physiological reaction of the workers. Pergamon press; 1960. p. 82108.

7. Borg G. Perceived exertion as an indicator of somatic stress. Scandinavian Journal of Rehabilitation Medicine.1977;2:92-8.

8. Nielsen R and Meyer J P. Evaluation of metabolism from heart rate in industrial work. Ergonomics 1987;30:565-72.

9. Malchaire J, Wallemacq M. Validity of oxygen consumption measurement at the workplace. What are we measuring? Annals of Occupational Hygiene 1984;28:189-93.

10. Lablanche-Combier B, Ley F. Utilisation de l'enregistrement electrocardiographique continu dans l'evaluation de la charge de travail des chantiers miniers chaud. Arch Mal Prof 1984;5:323-32

11. Chamoux A, Borel AM, Catilina P. Pour la standardisation d'une frequence cardiaque de repos. Arch Mal Prof. 1985;46:241-50.

12. Gertner A, Israeli R, Cassuto Y. Effects of work and motivation on the heart rate of the chronic heat exposed workers during their regular work shifts. Ergonomics 1984;27:135-40.

13. Green MS, Luz Y, Jucha E, Cocos M, Rosenberg N. Factors effecting ambulatory heart rate in industrial workers. Ergonomics 1986;29:101727.

14. Brabant C, Bedard S, Mergler D. Cardiac strain among women worker in an industrial laundry. Ergonomics 1989;32:615-28.

15. Costa G, Berti F, Betta A. Physiological cost of apple farming activities. Ergonomics 1989;20:281-86.

16. Åstrand I. Aerobic work capacity in men and women with special reference to age. Acta Physiol Scand 1960;49:69.

17. Grandjean E. Fitting the task to the man. $5^{\text {th }}$ edn. London. Taylor and Francis, 1988.

18. Åstrand PO, Rodahl K. Textbook of work physiology. New York: McGraw Hill; 1986. p. 501-2.

19. Ahonen E, Venäläinen M, Könönen U, Klen T. the physical strain of dairy farming. Ergonomics 1990;33:1549-55.

20. Rao MN, Saha PN. The Indian agriculturist. Journal of Occupational Medicine 1965;7:447.

21. Ramanamurthy P S V and Dakhyani R. Energy intake and expenditure in stone cutters. Indian Journal of Medical research.1962;43:57-61

22. Sen R N, Chatterjee S K, Saha P N and Subramanian A. Assessment of workload and thermal stress in cotton textile mill. Report No. 3. 1964;Central labour Institute. Sion, Bombay.

23. Sengupta A, Ferris BG, Rao MN. Oxygen consumption of male Indian jute worker. Archives of Industrial health 1959;20:96.

24. Mookherjee G and Sharma R N. A report on environmental comfort zone in tropics. Journal of science and industrial research 1953;6:283-7.

25. Lind AR. Evaluation of heat stress and strain. In: Leithed CS, lind AR, editors. London: Cassell and Co. Ltd; 1964. p. 44-78.

26. Lind AR. Effect of individual variation on upper limit of prescriptive zone of climates. Journal of applied physiology 1970;28:57-62.

27. Samanta A, Dutta SR, Roy BN. Recovery heart rate as a tool for the assessment of work stress. Indian journal of physiology and allied sciences 1984;38,123-8.

28. Ramanathan NL, Dutta SR, Roy BN, Chattrejee A, Mullick LN. Energy cost of different muscular exercise tests performed by Indian subjects. Indian journal of occupational heath 1967;10:253-61.

29. Saha PN, Dutta SR, Bannerjee PK, Narayane GG. An acceptable workload for Indian workers. Ergonomics 1979;22;1059-71.

30. Rutenfranz J, Ilmarinen J, Klimmer F, kylian H. Workload and demanded physical performance capacity under different industrial working conditions. In: M Kaneko, editor. Fitness for the aged, disabled and industrial worker, International series on Sports Sciences, 20. Champaign, IL: Human Kinetics Books; 1990. p. 217-38.

31. Evans WJ, Winsman FR, Pandolf KB, Goldman RF. Self-paced hard work comparing men and women. Ergonomics 1980;7:613-21. 